\title{
Strengthening of Hollow Square Sections under Compression Using FRP Composites
}

\author{
M. C. Sundarraja, ${ }^{1}$ P. Sriram, ${ }^{1}$ and G. Ganesh Prabhu ${ }^{2}$ \\ ${ }^{1}$ Departement of Civil Engineering, Thiagarajar College of Engineering, Tamil Nadu 625 015, India \\ ${ }^{2}$ Departement of Civil Engineering, Sethu Institute of Technology, Kariapatti, Virudhunagar, Tamilnadu 626115, India \\ Correspondence should be addressed to G. Ganesh Prabhu; gganeshprabhu@gmail.com
}

Received 4 November 2013; Revised 3 January 2014; Accepted 5 January 2014; Published 23 February 2014

Academic Editor: Bin Li

Copyright (C) 2014 M. C. Sundarraja et al. This is an open access article distributed under the Creative Commons Attribution License, which permits unrestricted use, distribution, and reproduction in any medium, provided the original work is properly cited.

\begin{abstract}
The feasibility study on carbon fibre reinforced polymer (CFRP) fabrics in axial strengthening of hollow square sections (HSS) was investigated in this paper. CFRP was used as strips form with other parameters such as the number of layers and spacing of strips. Experimental results revealed that the external bonding of normal modulus CFRP strips significantly enhanced the load carrying capacity and stiffness of the hollow sections and also reduced the axial shortening of columns by providing external confinement against the elastic deformation. The increase in the CFRP strips thickness effectively delayed the local buckling of the above members and led to the inward buckling rather than outward one. Finally, three-dimensional nonlinear finite element modeling of CFRP strengthened hollow square sectionswas created by using ANSYS 12.0 to validate the results and the numerical results such as failure modes and load deformation behaviour fairly agreed with the experimental results.
\end{abstract}

\section{Introduction}

Over the past few decades, the structural applications of hollow square sections (HSS) in offshore structures became widespread due to its numerous advantages such as light weight, high strength, large energy absorption capacity, high torsional rigidity, and adequate ductility to certain extents. And very recently, designers discovered its economical advantages as well. At the same time, aging and deterioration caused by exposure to the marine environment of tubular and metallic structures were often reported. In addition to that infrastructure concerned with metallic structures were found to be structurally unsatisfactory due to overloading and deficiency in the design phase. Hence, the engineers are constrained to implement new materials and effective strengthening technique to efficiently combat this problem. From the past, the research initiatives observed that external strengthening provides a practical and cost effective solution. The earliest investigators utilized steel plates for external strengthening. Though the technique was successful in practice, it posed some harms such as addition of self-weight, required heavy lifting equipment, difficulty in shaping and fitting in complex profiles, and complication in bonding/welding and further added plates are susceptible to corrosion which leads to an increase in future maintenance costs. In contrast, rehabilitation using fibre reinforced polymer (FRP) composites does not exhibit any of these drawbacks. The FRP composite materials were introduced in the year 1909. But the composite industry began to bloom only after 1930s [1]. First, the glass fibre reinforced polymers (GFRP) were used in aircraft radar covers at the end of 1930s [2] and FRP boat hulls and car bodies were developed with glass fibres as the major reinforcement. And also, glass fibre was used as an insulator to prevent galvanic corrosion of metals since it is a nonconductive material [3]. At the end of 1960s, Royal Aircraft Establishment had developed the carbon fibre reinforced polymer (CFRP) for special applications [4]. Unlike glass, carbon has very high stiffness of the same order as that of the steel and behaves very well against creep deformation and relaxation [1]. After introduction of advanced composite materials in construction industry, a second generation utilized those materials in external strengthening of structures. The CFRP has proved to be an excellent candidate for strengthening of reinforced concrete structures because of its superior mechanical, fatigue, 


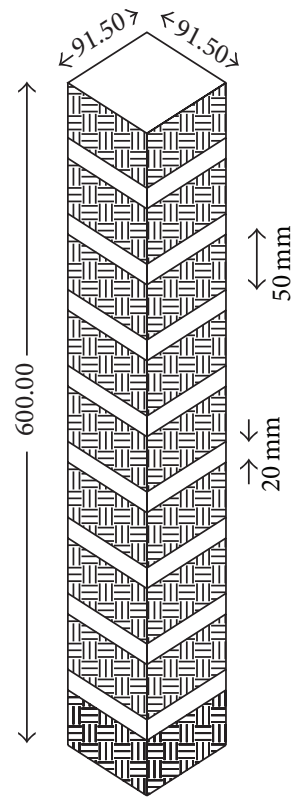

(a)

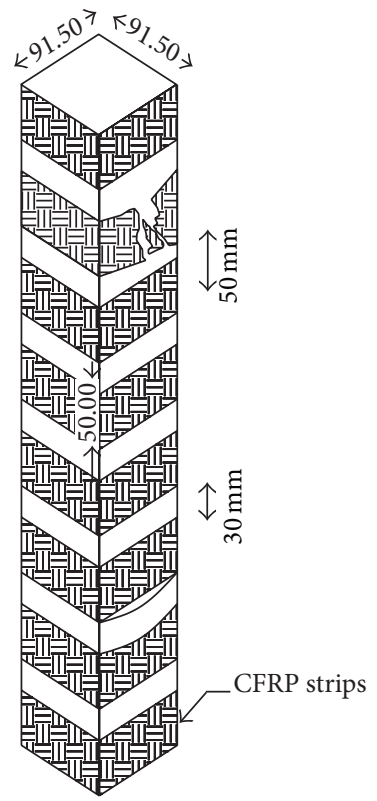

(b)

FIgURE 1: Wrapping Scheme (a) HS-50-20 (b) HS-50-30.

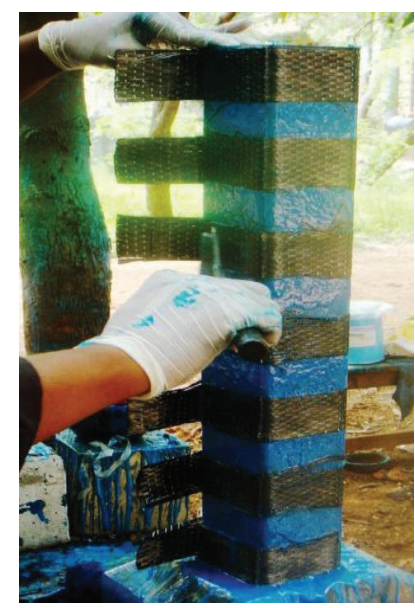

FIGURE 2: Squeezing of resin by steel roller.

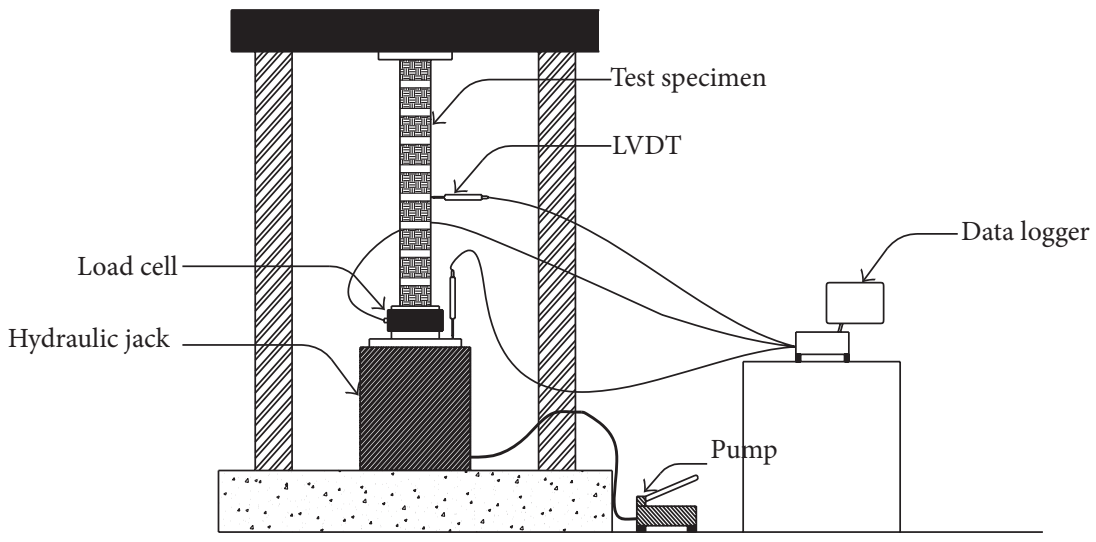

Figure 3: Experimental setup. 


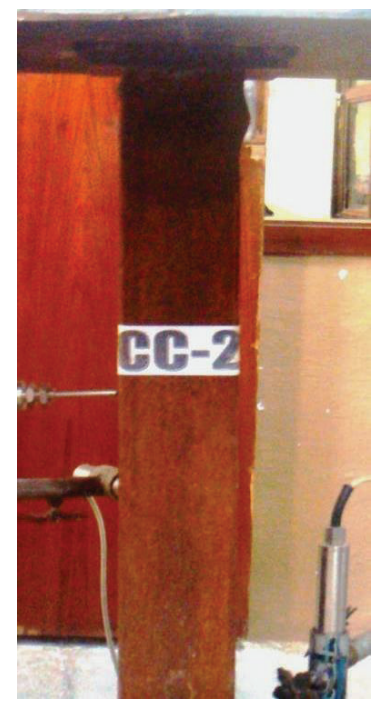

FIGURE 4: Failure mode of control column.

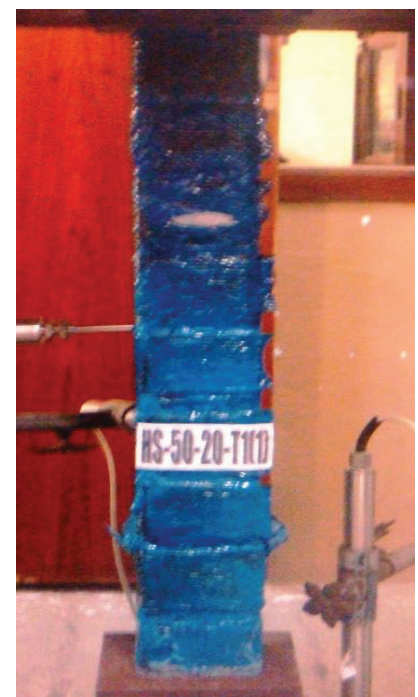

FIGURE 5: Failure mode of column HS-50-20-T1(1).

and in-service properties. However, research related to CFRP applications to steel structures has started quite recently and there are still few applications in practice due to uncertainties concerning the long term behaviour of these applications and the bonding between the composite materials and steel.

One of the first known studies on this topic that involved the use of CFRP laminates to repair steel structures was conducted by Sen and Liby [5]. Six composite beams were tested under four-point bending setup. An epoxy adhesive was used to wrap the CFRP laminates in the tension flange of the steel beam in different configurations. High strength steel bolts were also used in an attempt to increase the load transfer to the CFRP laminates Test results indicated that more modest improvement in the elastic response was required, even though significant ultimate strength was gained.

In another investigation, Jiao and Zhao [6] studied the performance of butt-welded very high strength (VHS) steel tubes strengthened with CFRP fabrics under axial tension. Three types of epoxy resins with different lap shear strengths were used. Three kinds of failure modes such as adhesive failure, fibre tear, and mixed failure were observed. The above investigation concluded that a significant strength can be achieved using CFRP-epoxy-strengthening technique and they also recommended a suitable epoxy adhesive for strengthening of VHS steel tubes.

Photiou et al. [7] investigated the effectiveness of an ultrahigh modulus and high modulus CFRP prepreg in strengthening the artificially degraded steel beam of rectangular cross-section under four-point loading by using two different wrapping configurations. The beam containing the ultrahigh modulus CFRP failed when the ultimate strain of the carbon fibre reached the pure moment region. In addition, the failure load exceeded the plastic collapse load of the undamaged beam. The beams strengthened by using the high 


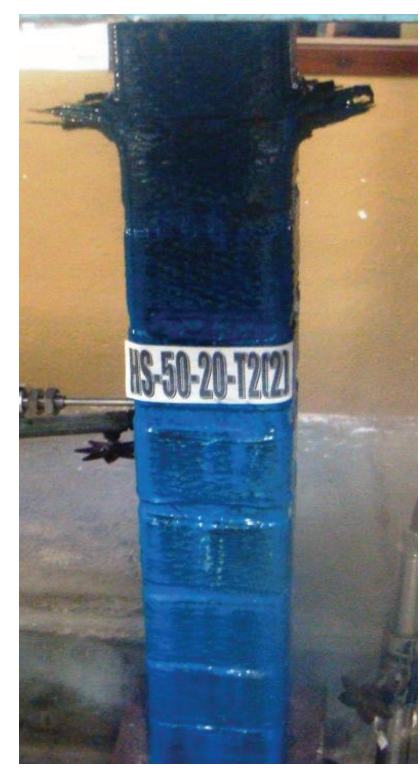

FIGURE 6: Failure mode of column HS-50-20-T2(2).

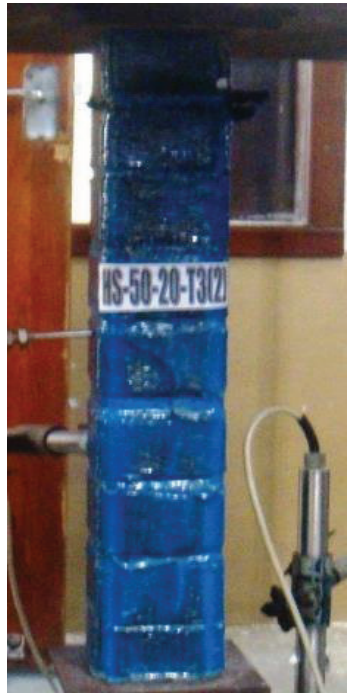

FIgURE 7: Failure mode of column HS-50-20-T3(2).

modulus CFRP exhibited ductile response leading to very high deflections even after higher ultimate load was reached.

Seica and Packer [8] investigated the FRP materials for the rehabilitation of tubular steel structures for underwater applications. Six tubes were wrapped with CFRP composites. Two specimens were prepared under in-air conditions and remaining four specimens were under seawater-curing conditions. The test results shown that the ultimate strength of the tubes wrapped under in-air and seawater-curing conditions have $16-27 \%$ and $8-21 \%$ more than that of bare steel beam, respectively.

Tao et al. [9] presented the results of axial compression and bending tests of fire-damaged concrete-filled steel tubes (CFST) repaired using unidirectional CFRP composites. Both circular and square specimens were tested to investigate the repair effects of CFRP composites on them. The test results showed that the load-carrying capacity and the longitudinal stiffness of CFRP-repaired CFST stub columns increased while their ductility decreased with the increasing number of CFRP layers. And also it was recommended that appropriate repair measures should be taken in repairing severely firedamaged CFST beams or those members subjected to comparatively large bending moments.

In another study, Tao and Han [10] repaired the fireexposed CFST beam columns by unidirectional CFRP composites. The test results revealed that the fibre jackets enhanced the load-bearing capacity to some extent, while the influence of CFRP repair on stiffness was not apparent.

Elchalakani and Fernando [11] studied the plastic mechanism analysis of unstiffened steel I-section beams 


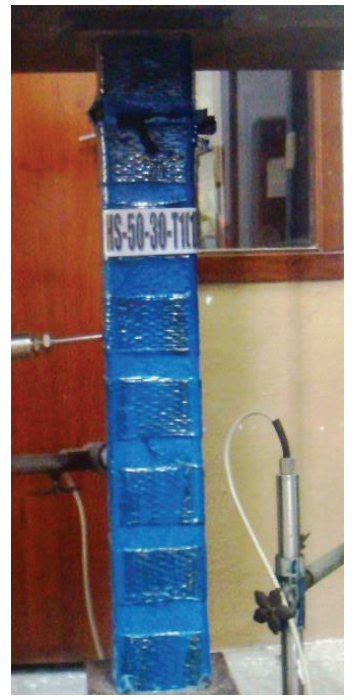

FIgURE 8: Failure mode of column HS-50-30-T1(1).

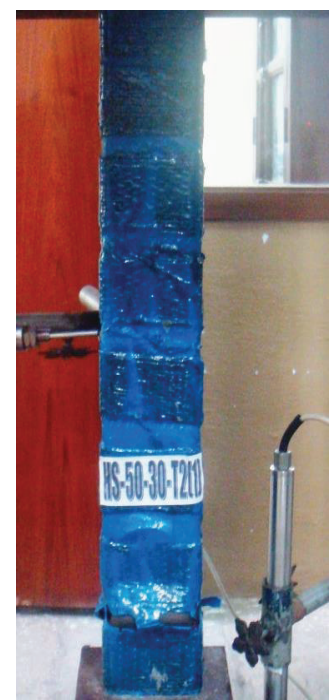

FIGURE 9: Failure mode of column HS-50-30-T2(1).

strengthened with CFRP composites. The CFRP plates were added with the specimens on the tension flange and with some specimens on both compression and tension flanges and some were bonded onto the whole section including the web. The results showed that the strength enhanced was by $32 \%$ for the specimens strengthened on both compression and tension flanges whereas it was by $15 \%$ in the case of specimens on tension flange only.

Recently, Narmashiri et al. [12] conducted both experimental and numerical investigations on the structural behaviour of steel I-beams flexurally strengthened by CFRP strips. Twelve beams were strengthened by using different types and dimensions of CFRP strips. Four types of failure modes were observed and their occurrences and sequences are varied on the strengthening schedule.

Kadhim [13] numerically investigated the behavior of I-beam strengthened with CFRP plate and the effect of strengthening length. The load-deflection response curves were predicted using finite element analysis (FEA) and were compared with experimental data. The analytical results showed that the length of CFRP plate increased the ultimate strength of beam when they reached $40 \%$ and $60 \%$ of span length in sagging and hogging regions, respectively.

$\mathrm{Wu}$ et al. [14] performed a series of experiments to evaluate the bond characteristics between ultrahigh modulus (UHM) CFRP laminate and steel by double strap joints. Different adhesives were used in order to compare their effectiveness when used for bonding UHM CFRP laminate with steel. Theoretical models were employed for the prediction of bond strength and effective bond length. The simulation results agreed well with experimentation under ultimate load, load extension curves, and bond-slip relationships.

Al-Zubaidy et al. [15] examined the bond characteristics between CFRP fabrics and steel plate joints under impact 


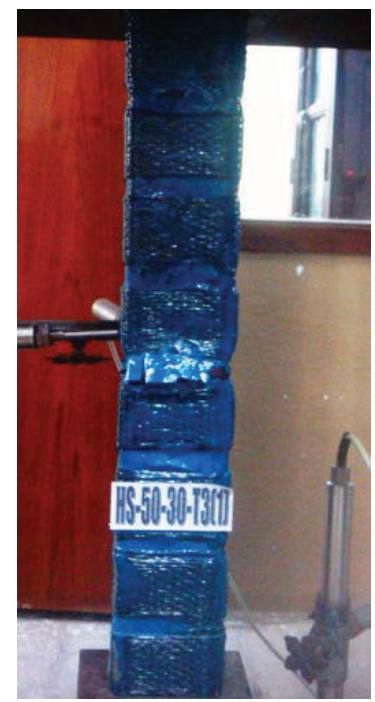

Figure 10: Failure mode of column HS-50-30-T3(1).

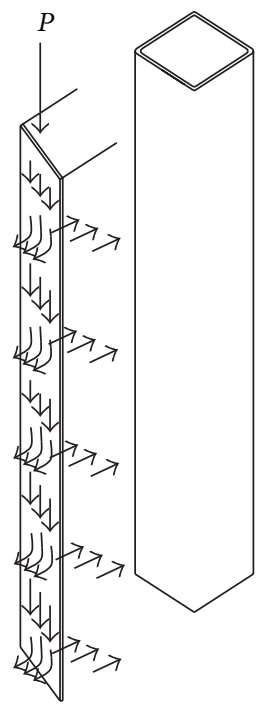

(a)

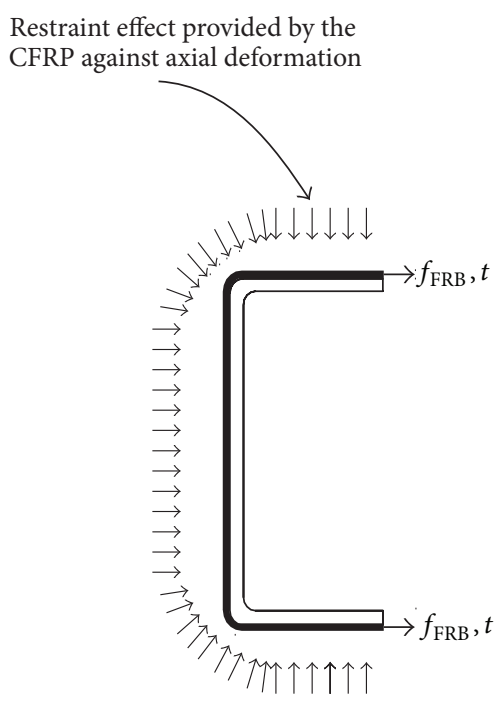

(b)

FIgURE 11: (a) Membrane strain in steel tube and (b) restraint effect by CFRP.

tensile loads. Different numbers of CFRP layers with different bond lengths were investigated. Experimental findings revealed that the effective bond length is insensitive to loading rate for both joints and in addition the maximum improvement in joint capacity occurred at a rate of $3.35 \mathrm{~m} / \mathrm{s}$.

Colombi and Fava [16] investigated the fatigue performance of tensile steel/CFRP double shear lap joints. Fatigue tests were performed on specimens under constant stress range loading cycles. The debonding of fibre was observed at stress concentration zones and propagated along the CFRP/adhesive interfaces.

From the past research, it can be observed that there have been investigations done with the use of CFRP fabrics as a strengthening material for metallic members and also the presence of CFRP significantly enhanced the structural behaviour of steel tubular members. However, research related to strengthening of hollow sections using FRP strips composites is not widespread and also more experiments are required to derive an optimal combination of fibre orientation, number of layers, and sequence in applying CFRP layers. The main objective of the investigation is to experimentally investigate the suitability of carbon fibre reinforced polymer strips in strengthening the corroded tubular members under compression and also compare the effectiveness of geometric shapes (i.e., wrapping scheme) of the upgrading material. To eliminate the galvanic corrosion between steel tube and CFRP fabrics, a thin layer of glass fibre mat was introduced between them. 


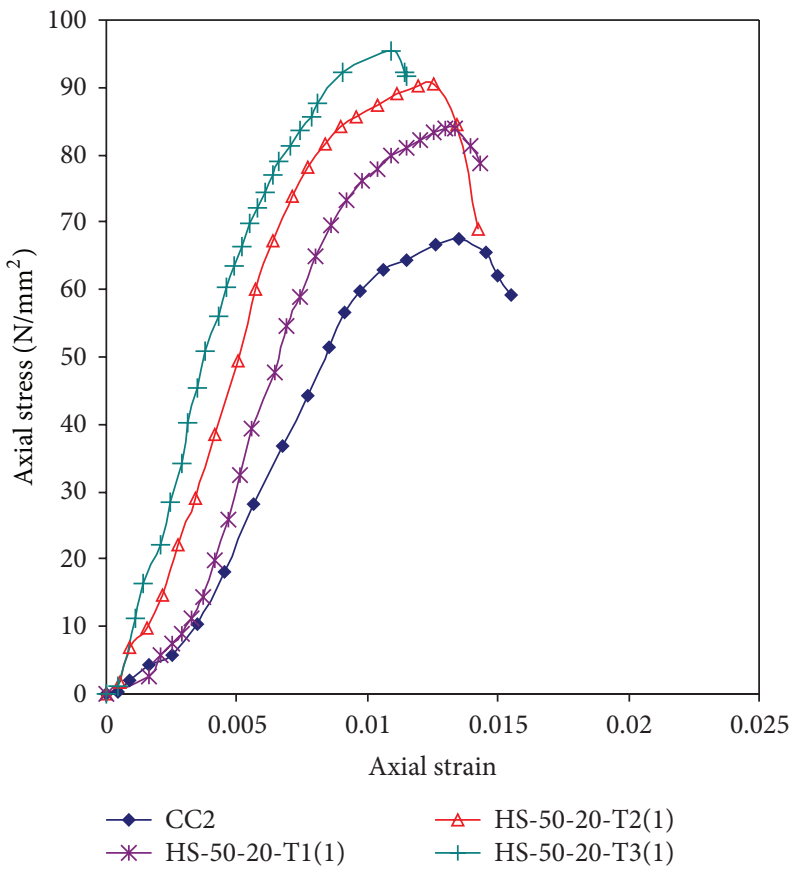

FIGURE 12: Axial stress-strain behaviour of columns HS-50-20-comparison.

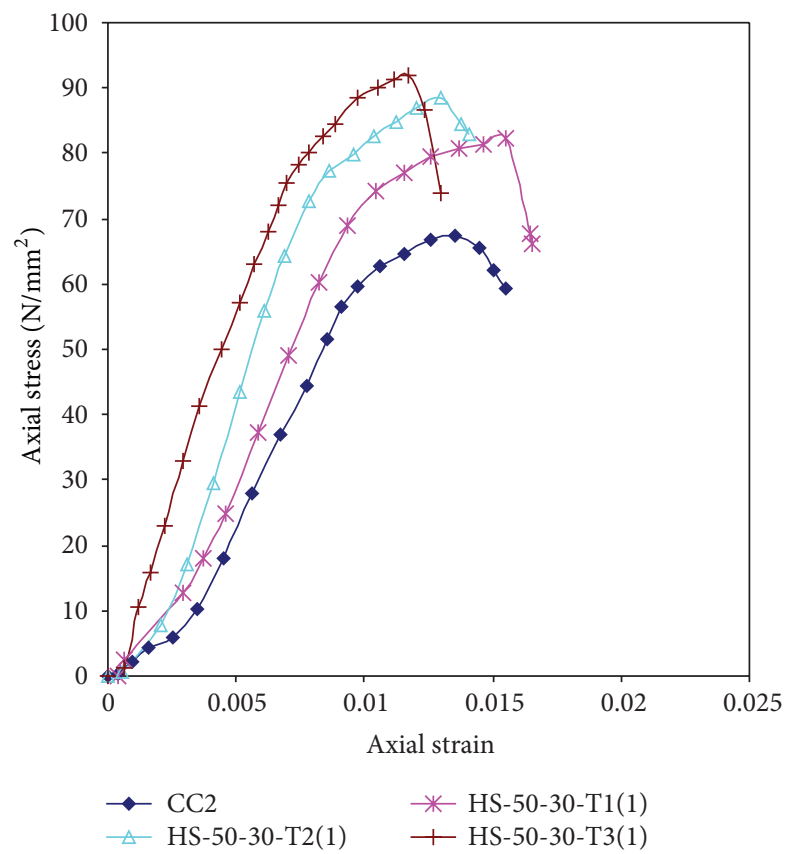

FIGURE 13: Axial stress-strain behaviour of columns HS-50-30-comparison.

\section{Materials}

2.1. Carbon Fibre. The unidirectional carbon fibre called MBrace 240 fabricated by BASF India Inc was used in this study. It is a low modulus CFRP fibre having modulus of elasticity of $240 \mathrm{kN} / \mathrm{mm}^{2}$ and the tensile strength of $3800 \mathrm{~N} /$ $\mathrm{mm}^{2}$. The thickness and width of the fibre were $0.234 \mathrm{~mm}$ and
$600 \mathrm{~mm}$, respectively. It is a fabric type and can be tailored to any desired shape.

2.2. Adhesive. The MBrace saturant supplied by BASF India Inc was used in this study to get sufficient bonding between steel tube and carbon fibre. It is a two-part system, a resin and a hardener, and the mixing ratio was $100: 40(\mathrm{~B}: \mathrm{H})$. 


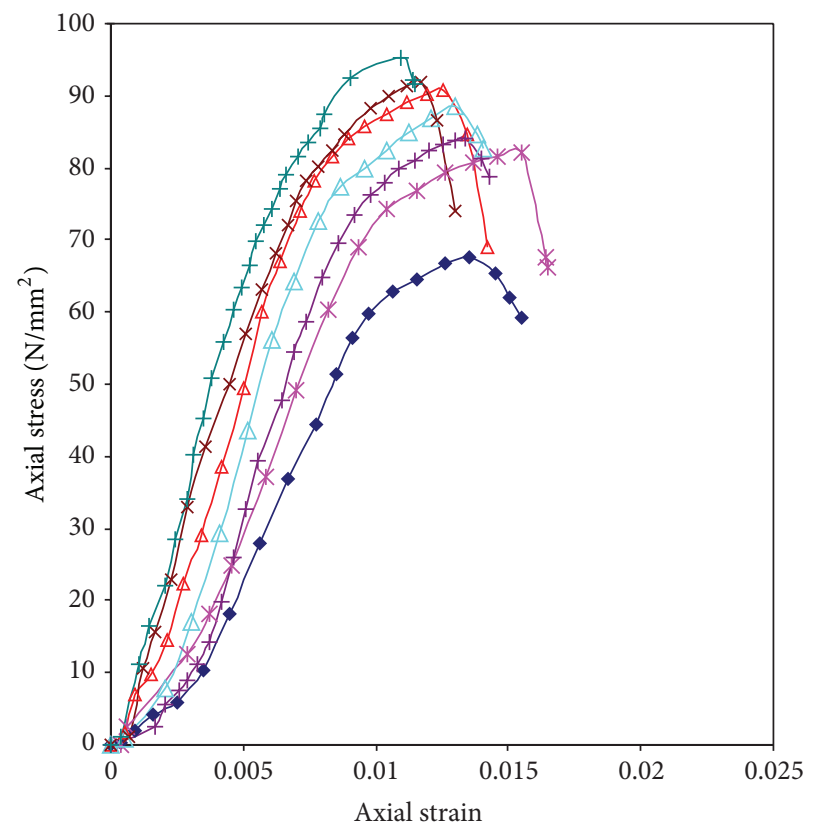

$$
\begin{array}{ll}
\triangle \text { HS-50-20-T2(1) } & \triangle \text { HS-50-30-T2(1) } \\
+ \text { HS-50-20-T1(1) } & \rightarrow \text { HS-50-30-T3(1) } \\
+ \text { HS-50-20-T3(1) } & \rightarrow \text { CC2 } \\
\rightarrow \text { HS-50-30-T1(1) } &
\end{array}
$$

FIGURE 14: Axial stress-strain behaviours of all columns-comparison.

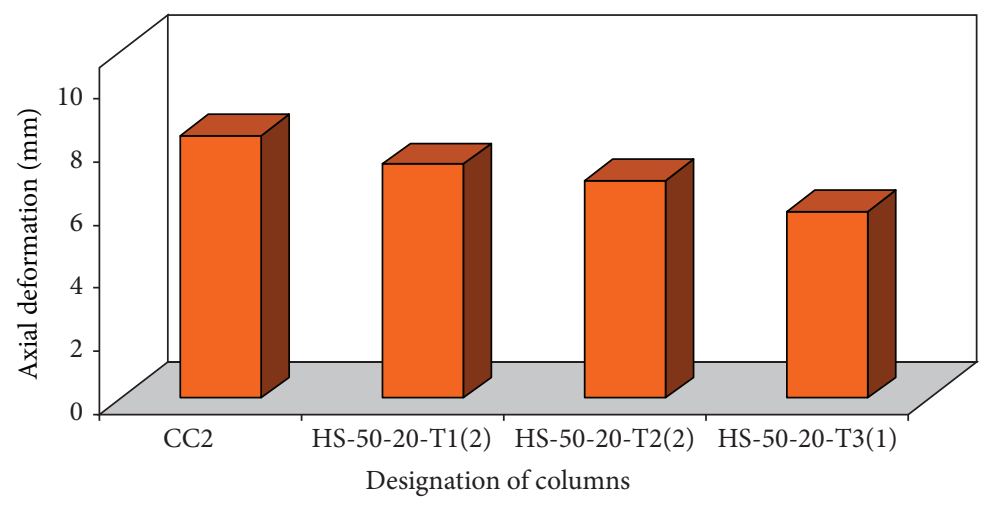

FIgURE 15: Axial deformation for columns HS-50-20—comparison.

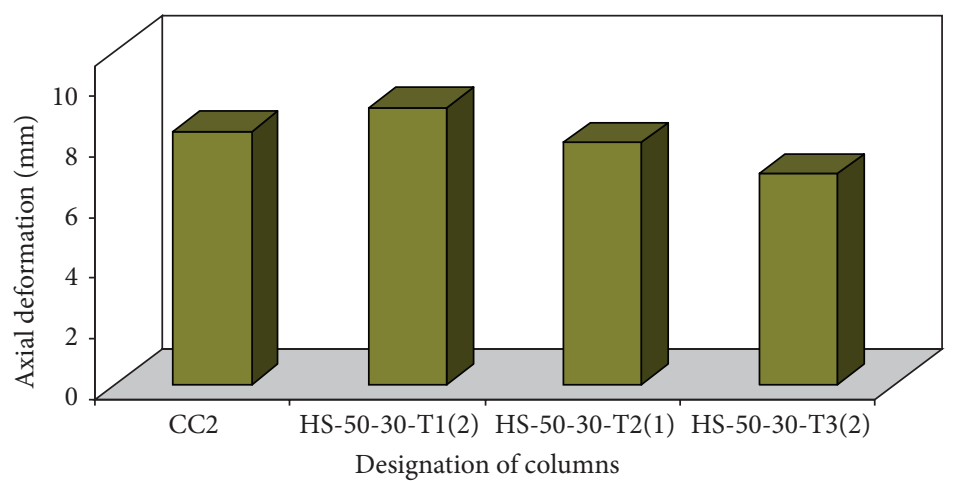

Figure 16: Axial deformation for columns HS-50-30—comparison. 


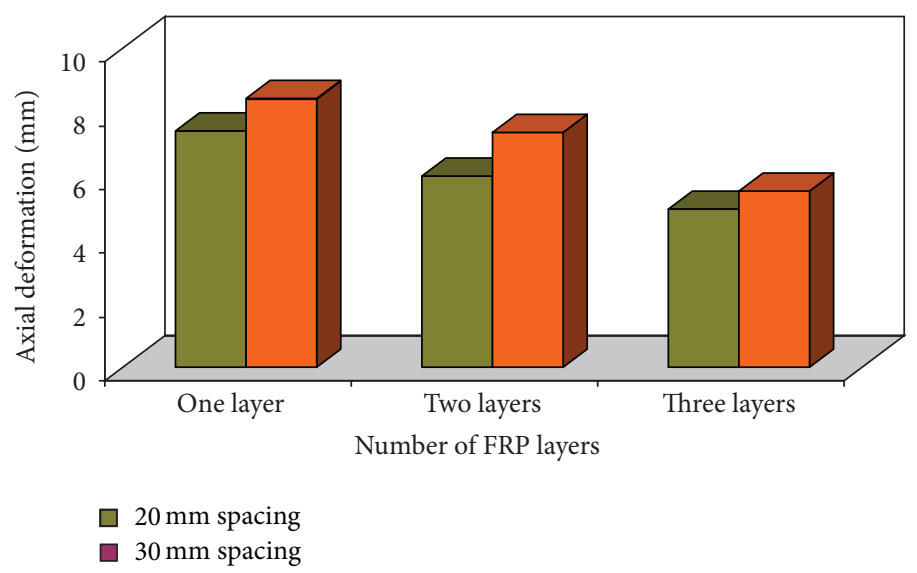

Figure 17: Axial deformation for all columns-comparison.

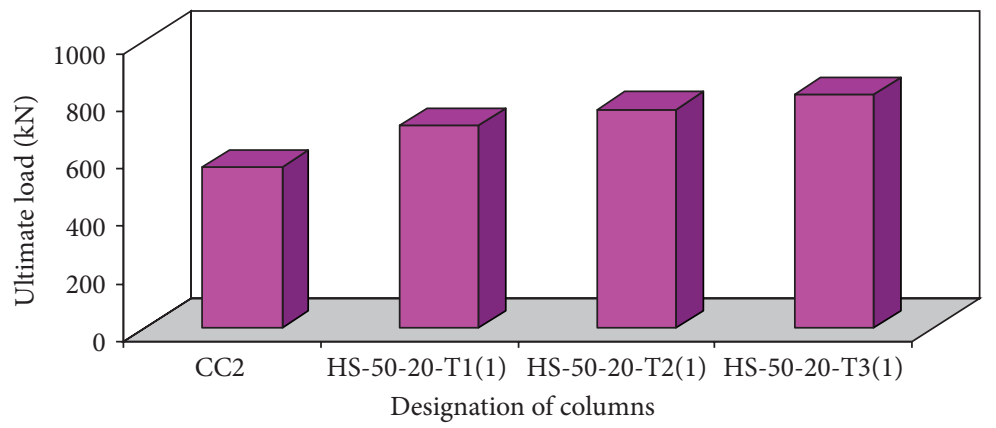

FIGURE 18: Ultimate load for columns HS-50-20-comparison.

2.3. Steel Tube. The square hollow steel tube confirming to IS 4923-1997 and having a dimension of $91.5 \mathrm{~mm} \times 91.5 \mathrm{~mm}$ was used in this study. The thickness and height of the square hollow steel tube were $3.6 \mathrm{~mm}$ and $600 \mathrm{~mm}$, respectively. The yield strength of the tube was $249 \mathrm{MPa}$ and found from the experimental values.

\section{Experimental Program}

3.1. Specimen Fabrication. At some stages of loading, the hollow sections have undergone large deformation and the membrane strain was triggered in both directions when the tube started to elastically buckle. Haedir et al. $[17,18]$ predicted that the strength of short circular column was enhanced when reinforced with CFRP layers in transverse direction compared to the column with longitudinal layers. Based on the above, in this investigation, all the columns were aimed to strengthen with CFRP fabrics in transverse direction. The hollow sections of $600 \mathrm{~mm}$ height were machined from $6 \mathrm{~m}$ length hollow tubes. Surface preparation of the metal substrate is very important to achieve good bonding between the steel tube and CFRP fabrics. Hence, the exposed degraded surfaces of the tubular specimens were sand blasted in order to make the surface rough one. Then the surface of the specimens was cleaned by using acetone to remove all contaminant materials [19]. Prior to bonding CFRP, a thin layer of glass fibre fabric was introduced between the steel surface and CFRP composites in order to eliminate the galvanic corrosion. During wrapping of fibre fabrics, the resin and hardener were correctly proportioned and thoroughly mixed together and the excess epoxy and air were removed using a ribbed roller moving in the direction of the fibre which is shown in Figure 2.

3.2. Experimental Setup. The hollow sections were tested in compression testing machine of capacity $2000 \mathrm{kN}$. Each member was positioned on the supports taking care to ensure that its centreline was exactly in line with the axis of the machine. The verticality of the specimens was checked using plumb bob and sprit level. The specimens were instrumented to measure longitudinal axial compression. The load was applied to the column by hydraulic jack and monitored by using $1000 \mathrm{kN}$ capacity load cell. Axial deformation of the column was measured by using linear voltage displacement transducer (LVDT) which was kept at top of the jack [20]. The load cell and LVDT were connected with the 16-Channel Data Acquisition System to store the respective data. At the beginning, a small load of $20 \mathrm{kN}$ was applied slowly, so that the columns settled properly on thier supports. Then the load was removed after checking the proper functioning of the instrumentation. The trial load was applied again slowly and the column was then tested to failure by applying the compressive load in small increments and the observations such as axial deformation and the ultimate load were carefully 


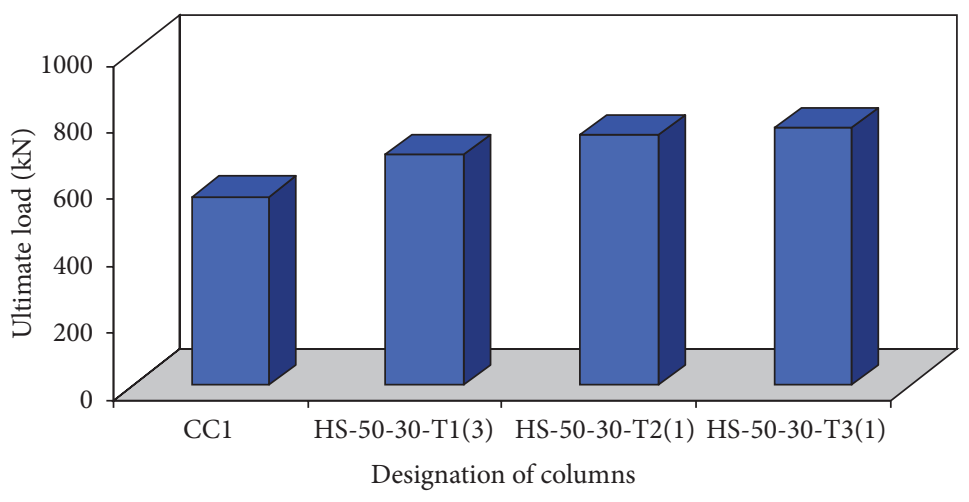

FIGURE 19: Ultimate load for columns HS-50-30—comparison.

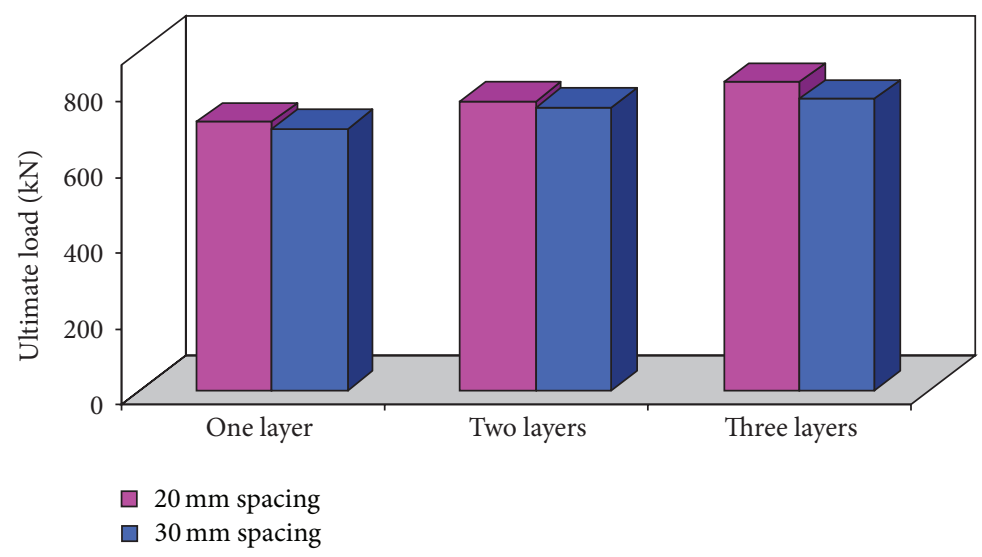

FIGURE 20: Ultimate load for all columns-comparison.

recorded. The load at which the CFRP starts rupturing and the nature of failure were also noted for each column. The experimental setup is shown in Figure 3.

3.3. Description of Specimens. Among twenty-one specimens, eighteen were externally bonded by CFRP strips having a constant width of $50 \mathrm{~mm}$ wrapped with the spacing of $20 \mathrm{~mm}$ and $30 \mathrm{~mm}$ and the remaining three specimens were unbonded. The wrapping schemes are shown in Figure 1. The size and length of the columns used were $91.5 \times 91.5 \times 3.6 \mathrm{~mm}$ and $600 \mathrm{~mm}$, respectively. To identify the specimen easily, the columns were designated with names such as HS-50-20T1, HS-50-20-T2, HS-50-20-T3, HS-50-30-T1, HS-50-30-T2, and HS-50-30-T3. For example, the specimen HS-50-20-T3 specifies that it was strengthened by three (3) layers of $50 \mathrm{~mm}$ width horizontal strip (HS) of CFRP fabrics in transverse direction (T) with the spacing of $20 \mathrm{~mm}$. The control columns are specified as $\mathrm{CC} 1, \mathrm{CC} 2$, and CC3.

\section{Results and Discussion}

4.1. Failure Modes. The failure modes of all tested columns are shown in Figures 4 to 10. All the specimens were tested until failure to fully understand the influence of FRP characteristics on their axial behaviour. In the case of control specimens (CC1, CC2, and CC3), both inward and outward buckling were observed on all four sides at the respective load of $546 \mathrm{kN}, 564 \mathrm{kN}$, and $549 \mathrm{kN}$ and is shown in Figure 4. The outward buckling was observed at the ends causing rupture of CFRP due to hoop tension in the case of columns bonded with one and two layers of CFRP strips with the spacing of $20 \mathrm{~mm}$ which are shown in Figures 5 and 6, and in addition no rupture of fibre was observed in other locations. When increasing the number of layers from two to three, the failure was turned into inward buckling rather than outward observed at the top ends of the specimen which is shown in Figure 7. It is the common failure mode, and since the thickness of the CFRP increases, the outward deformation is significantly restrained by the CFRP and as a result inward buckling of steel tube occurred. But it has been noted that, in all specimens above, no debonding of fibre was observed before attaining their ultimate load, and hence it can be confirmed that there was a perfect bond between the steel and CFRP in all cases and it may be considered as fully bonded steel-CFRP composite plate. In addition, after rupture of CFRP, an abrupt reduction in load was observed and this may be due to the immediate absence of confinement pressure provided by the CFRP.

When increasing the spacing of CFRP strips from $20 \mathrm{~mm}$ to $30 \mathrm{~mm}$, all the specimens that failed by local buckling of steel tube alone in unbonded region and without any rupture of fibre which are shown in Figures 8, 9, and 10. From the 


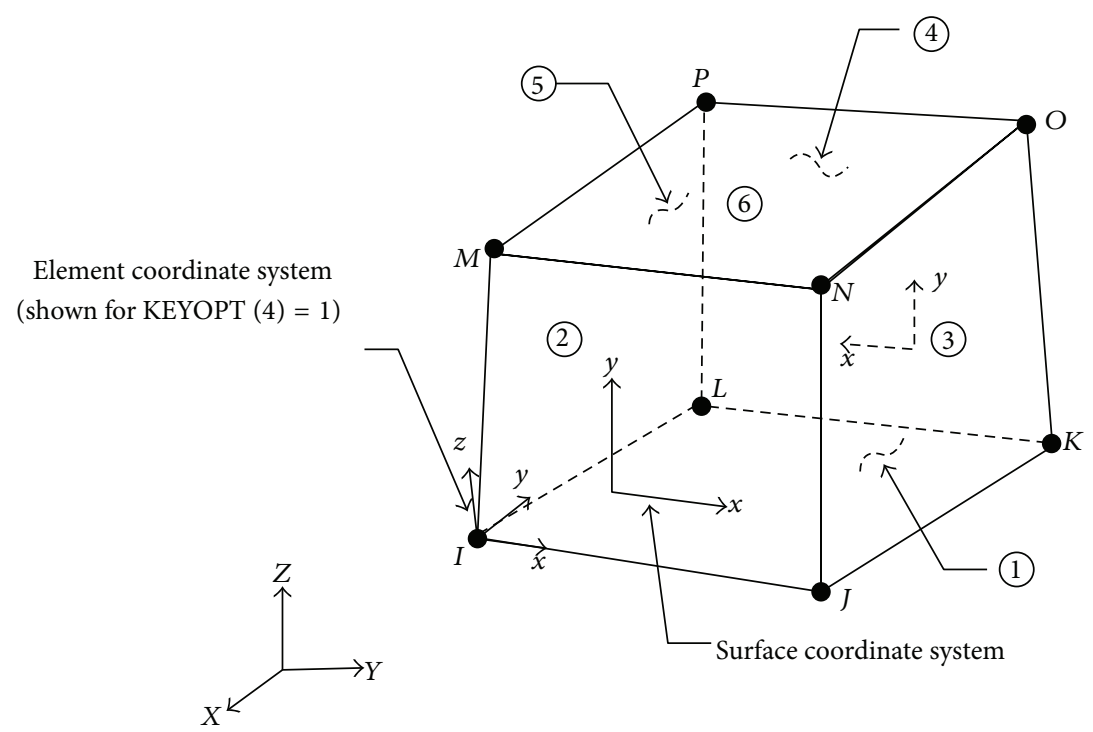

FIgURE 21: Solid45 element 3D solid (ANSYS12.0).

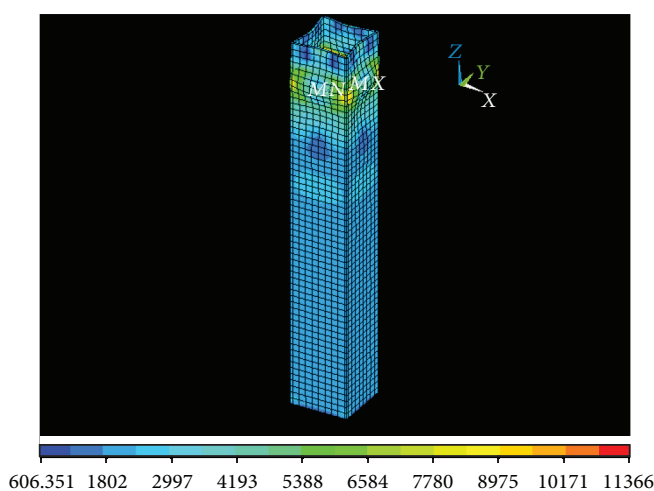

FIgURE 22: Typical computed deformed shapes of CC.

above observations, it can be noted that when increasing the spacing of CFRP strips, the unbonded area will become more and it was subjected to maximum strain during loading and consequently buckling of steel tube occurred in the unwrapped zone due to the absence of confinement pressure provided by the CFRP composites.

4.2. Axial Stress-Strain Behavior. The square hollow steel tube may be considered as stiffened plates and by assuming that their both longitudinal edges are fixed, the slenderness ratio of the plate calculated by the following equation (1) is proposed by Seica and Packer [8]:

$$
\begin{gathered}
\lambda=\sqrt{\frac{f_{y}}{f_{c r}}} \\
f_{c r}=\frac{k \pi^{2} E}{12\left(1-v^{2}\right)}\left(\frac{t}{b}\right)^{2},
\end{gathered}
$$

where $f_{y}$ and $f_{c r}$ (the stress at which a material failed by crippling/buckling) are the yield stress and ultimate elastic buckling stress respectively. The yield stress $\left(f_{y}\right)$ can be defined as the stress at which a material begins to deform plastically which was obtained from the steel coupon test. The elastic buckling stress, can be defined as the stress at which materials failed by crippling/buckling, which was obtained form the equation proposed by Seica and Packer [8]. $t$ and $b$ are the thickness and width of the plate and $v$ and $E$ are the poisons ratio and Young's modulus of the plate. For stiffened element, the buckling coefficient of the plate was taken as 4.0 [8].

Table 1 shows the slenderness value, maximum axial deformation, average experimental buckling stress, and percentage of enhancement in axial deformation control of the strengthened columns compared to CC2. From Figures 12 to 17 , it was observed that external bonding of CFRP fabrics effectively delayed the local buckling of the steel tube and also reduced the axial shortening by providing external confinement against the elastic deformation which is shown in Figure 11. At some stages in loading, the plates in the members have undergone large deformation and the membrane strain was triggered in both directions, which is shown in Figure 11(a). In the meantime, CFRP that lies in the outer limits started to resist lateral and axial strains by providing 


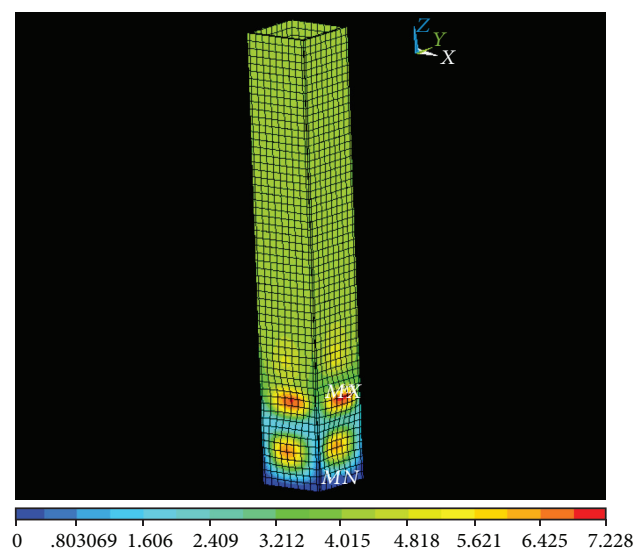

Figure 23: Typical computed deformed shapes of HS-50-20-T1.

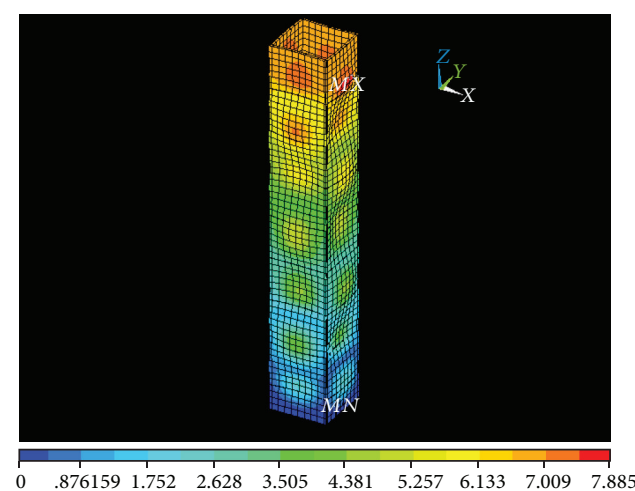

FIgURE 24: Typical computed deformed shapes of HS-50-20-T2.

confinement pressure as they were subjected to tension in the hoop direction as shown in Figure 11(b). That confining pressure exerted by the CFRP strips composites against the axial deformation can be called the restrained effect. Compared to control specimens, the columns HS-50-20-T1(1), HS-50-20T2(1), and HS-50-20-T3(1) enhanced their restraining effect by $68.68 \%, 116.88 \%$, and $163.40 \%$ respectively, and significant fall in curve was observed at the peak stage due to sudden rupture of CFRP. The addition of number of layers that provides further enhancement in buckling stress is shown in Figures 12 and 15. From the above observations, it can be seen that bonding of CFRP fabrics increases the thickness of the steel tube and decreases the slenderness value of the composite plate and as a result, the elastic buckling stress of the steel tube increased. In addition to that the enhancement in buckling stress due to addition of layers was not proportional. The above nonlinearity in buckling stress when increasing the number of fibre layers may be attributed to crushing of resin lying in-between the fibres. When the resin started to crush, a sudden drop in substantial load transfer occurred and as a result, nonlinearity in axial deformation control was observed. At the respective failure load of specimens such as HS-50-20-T1(1) and HS-50-20-T2(1), the axial deformation of a specimen HS-50-20-T3(1) observed was $4.57 \mathrm{~mm}$ and $5.13 \mathrm{~mm}$, respectively, and furthermore this deflection was $25 \%$ to $80 \%$ lesser than that of specimens
HS-50-20-T1(1) and HS-50-20-T2(1) which is shown in Figure 15. When increasing the spacing of FRP strips from $20 \mathrm{~mm}$ to $30 \mathrm{~mm}$, the above similar behaviour was observed in those columns; besides, the buckling stresses of the columns were reduced. The enhancements in restraining effect against axial deformation provided by the specimens HS-50-30-T1(1), HS-50-30-T2(1), and HS-50-30-T3(1) were $53.21 \%, 92.39 \%$, and $125.67 \%$, respectively, compared to the column CC2 which is shown in Figures 13 and 16. The experimental stress-strain behaviour of all columns is presented in Figure 14. The column HS-50-30-T1(2) that has higher axial deformation of $9.12 \mathrm{~mm}$ compared to column HS-50-20-T1(2) which has an axial deformation of $7.45 \mathrm{~mm}$ is shown in Figure 17. And also, the column HS-50-20T2(2) tends to have more capability of controlling axial deformation compared to column HS-50-30-T2(1). Figure 17 also illustrates that the column HS-50-30-T3(1) has more axial deformation $(7.02 \mathrm{~mm}$ ) than of column HS-50-20-T3(1) $(6.12 \mathrm{~mm})$ which is $14.7 \%$ less than HS-50-20-T3(1). This is a result of the fact that, when increasing the spacing of fibre strips, the unbonded area will become more and as a result, reduction in restraint provided by the CFRP strips against the axial deformation was observed.

4.3. Load Carrying Capacity. The experimental ultimate strength and the percentage of enhancement in it resulting 


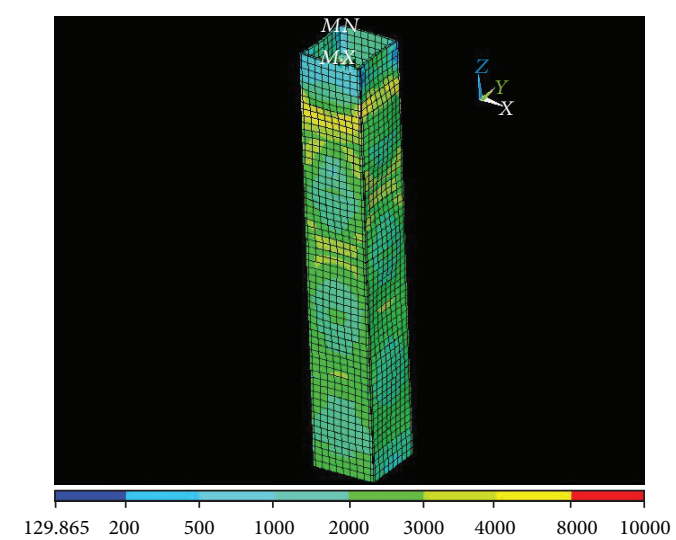

FIGURE 25: Typical computed deformed shapes of HS-50-20-T3.

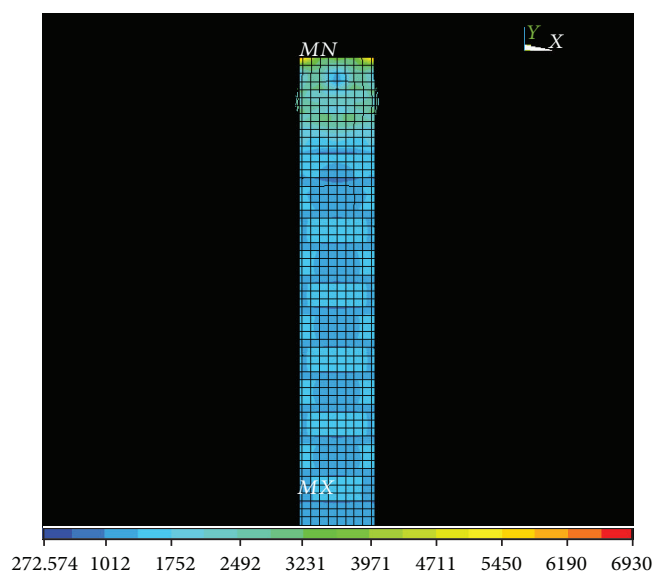

FIGURE 26: Typical computed deformed shapes of HS-50-30-T1.

from the bonding of CFRP strips with various spacing are presented in Table 1 . The load carrying capacity of the column can be defined as the column ability to resist the axial load. The graphical representation of enhancement in ultimate strength against number of layers is given in Figures 18 to 20. From that, it is confirmed that significant enhancement in ultimate strength can be achieved with the application of CFRP strips, especially up to $44.32 \%$ more than that of bare steel tube. The load at which the column failed was considered as a maximum axial force or ultimate strength. Compared to control column (CC1), the specimens HS-50-20-T1(1), HS50-20-T2(1), and HS-50-20-T3(1) enhanced their axial load carrying capacity by $25.71 \%, 35.46 \%$, and $44.32 \%$ as shown in Figure 18. In similar manner, the columns wrapped with $30 \mathrm{~mm}$ spacing of CFRP strips such as HS-50-30-T1(3), HS50-30-T2(1), and HS-50-30-T3(1) have 22.51\%, 32.8\%, and $36.52 \%$, respectively, more load carrying capacity than that of control column as shown in Figure 19. This informs that external bonding of CFRP strips provided sufficient restraining effect against deformation and also delayed the local buckling of steel tube and as a result the ultimate strength capacity was increased. From Figures 18 and 19, it is cleared that increase in number of CFRP layers enhanced the ultimate strength capacity of the steel tube; however, the enhancement in ultimate strength due to addition of layers was not proportional. As said earlier, this is a result of the fact that by increasing CFRP layers, the composite plate thickness is also increased and as a result, the elastic buckling stress/ultimate strength of the steel tube increased. The column HS-50-20T3(1) enhanced its axial load carrying capacity by $17.63 \%$ and $8.9 \%$ more than the columns HS-50-20-T1(2) and HS50-20-T2(2), respectively. Similarly, the column HS-50-30T3(1) enhanced its load carrying capacity by $12.9 \%$ and $4.19 \%$ compared to columns HS-50-30-T1(2) and HS-5030-T2(3), respectively. From Figure 20, it is also confirmed that the columns strengthened by CFRP strips with smaller spacing have more ultimate strength, and increase in ultimate strength mainly depends on the proper designed spacing of CFRP strips. When compared to column HS-50-30-T1(3), the column HS-50-20-T1(2) has more load carrying capacity and also the column HS-50-20-T2(1) enhanced its load carrying capacity by $2 \%$ compared with the column HS-50-30-T2(1). Figure 20 also illustrates that the column HS-50-20-T3(1) has more axial load carrying capacity $(814 \mathrm{kN})$ than column HS$50-30-\mathrm{T} 3(1)(770 \mathrm{kN})$ and which is $5.71 \%$ more than HS-5030-T3(1). From the above observations, it can be suggested that more benefit can be achieved by the bonding of CFRP strips having a spacing of $20 \mathrm{~mm}$. 


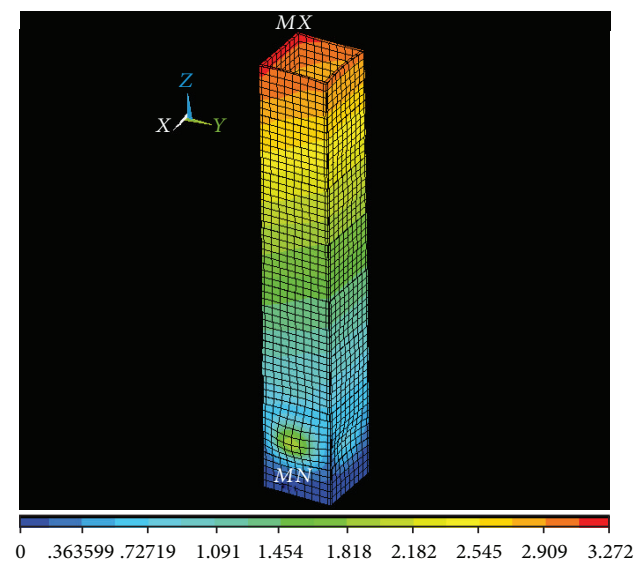

FIgURE 27: Typical computed deformed shapes of HS-50-20-T2.

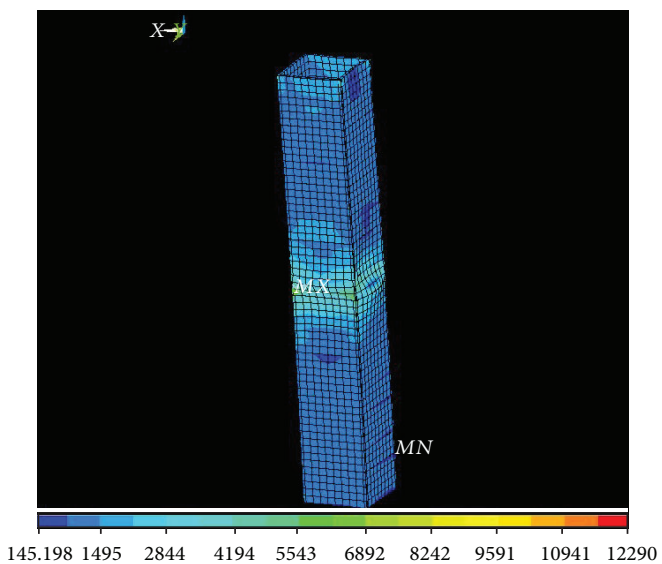

FIgURE 28: Typical computed deformed shapes of HS-50-20-T3.

\section{Finite Element Modelling}

Three-dimensional non-linear finite element modeling of CFRP strengthened tubular members were created by using finite element package ANSYS12.0 to validate the results with the experimental results. The measured thickness of the CFRP and the cross-sectional dimension of the specimen were used in the numerical modelling. An eight-node solid element (Solid45) was used to model the steel tubes and CFRP fabrics, which is shown in Figure 21. The element is defined by eight nodes having three degrees-of-freedom at each node and eight translations in the nodal directions $x, y$, and $z$. Perfect bond between the steel and FRP sheets was assumed. This assumption is quite reasonable as no signs of delamination were observed experimentally [21]. The full transient structural analyses (time-history analysis or load-deformation analysis) were performed to predict the load-deformation behavior of the strengthened columns. The bottom surface of the tube was made rigid and constrained in all degrees of freedom and the top surface of the steel tube was constrained in all degrees-of -freedom except in the $y$-direction [22]. Regarding the application of load, loads are applied incrementally by means of an equivalent displacement to overcome convergence problems. The load step increments are varied in order to solve potential numerical problems.

5.1. Material Properties. The nonlinear behaviour of the steel tube was modeled by specifying yield stress and tangent modulus. The tangent modulus of the steel was assumed as 0.5 percentage of its Young's modulus [21] and the yield stress $250 \mathrm{MPa}$ was found from the experimental values. The isotropic properties such as Young's modulus and Poisson's ratio of the mild steel tubes were also chosen from the experimental values and were about $210 \mathrm{GPa}$ and 0.3 , respectively. The FRP composites are considered as an orthotropic material; that is, their properties are not the same in all directions. The thickness of single composite layer was $0.5 \mathrm{~mm}$, which is epoxy coated fibre thickness [22]. And the unidirectional elastic properties, namely, Young's modulus and Poisson's ratio, were assigned as $240 \mathrm{GPa}$ and 0.22 respectively. For analysis, the density of concrete, steel and CFRP was assigned as $2500 \mathrm{~kg} / \mathrm{m}^{3}, 7850 \mathrm{~kg} / \mathrm{m}^{3}$, and $1720 \mathrm{~kg} / \mathrm{m}^{3}$, respectively.

5.2. Numerical Results. The nonlinear solution of the simulated models was run in ANSYS12.0 and the results obtained from numerical study fairly matched with experimental 


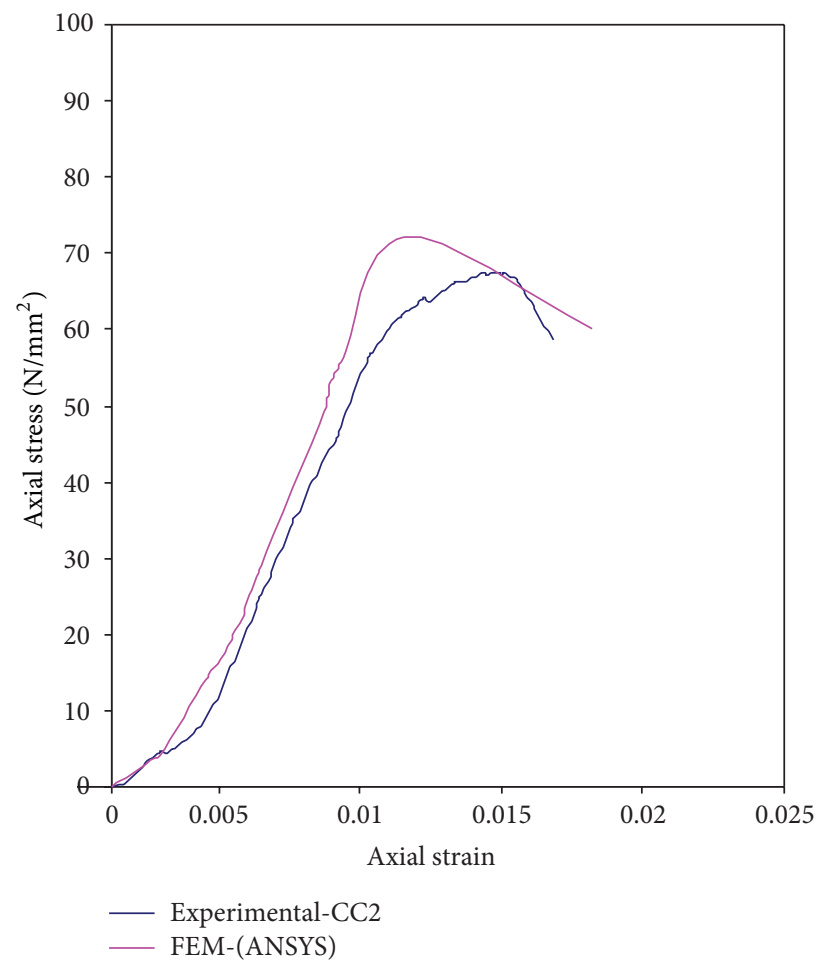

FIGURE 29: Comparison of experimental and computed axial stress-strain behaviours of control columns.

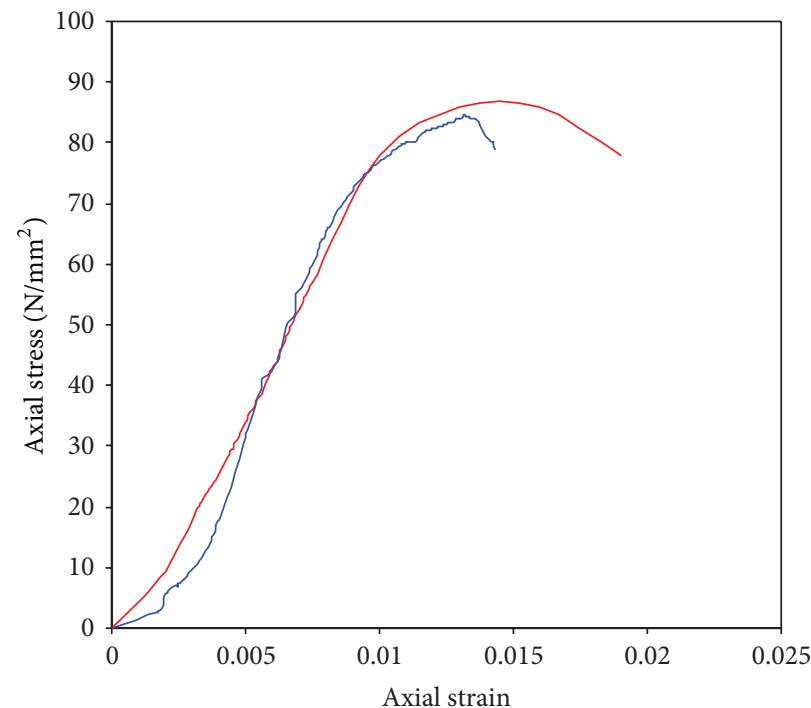

- FEM-HS-50-20-T1(1)

— HS-50-20-T1(1)

FIGURE 30: Comparison of experimental and computed axial stress-strain behaviours of HS-50-20-T1(1) columns.

study. The deformed shapes of the columns obtained by numerical simulation fairly agreed with the corresponding experimental results. In the numerical modeling, the failure mode of column with the spacing of $20 \mathrm{~mm}$ was rupture of fibre followed by outward buckling of steel tube whereas the column with the spacing of $30 \mathrm{~mm}$ collapsed by local buckling of steel tube, which is shown in Figures 22, 23, 24,
$25,26,27$, and 28 . The above same type of failure mode was observed during experimentation. Computational loaddeformation behavior of CFRP strengthened columns were also compared with experimental results and are represented in Figures 29 to 35. The load deformation curve obtained by numerical simulation for all strengthened columns exhibited linear elastic behavior until it reached the failure load of 


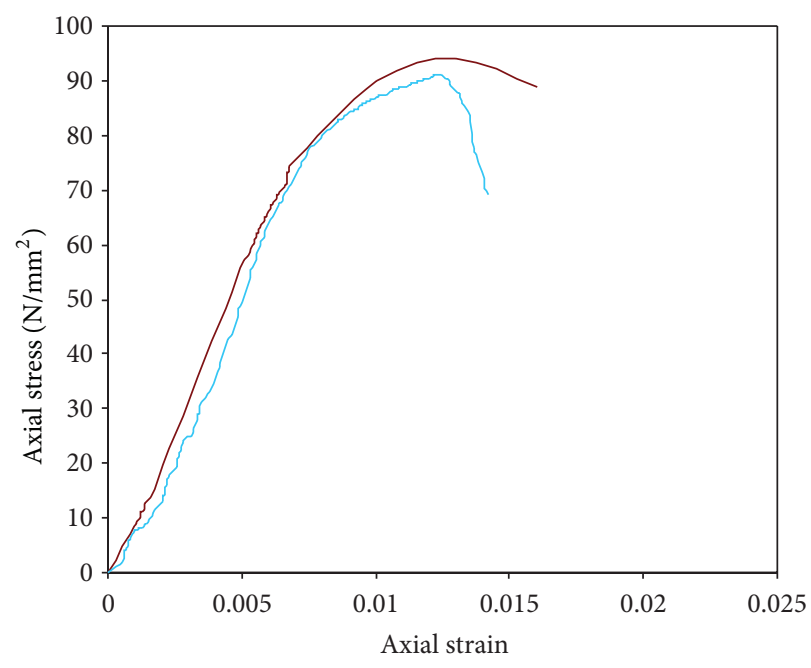

FEM-HS-50-20-T2(1)

HS-50-20-T2(1)

FIGURE 31: Comparison of experimental and computed axial stress-strain behaviours of HS-50-20-T2(1) columns.

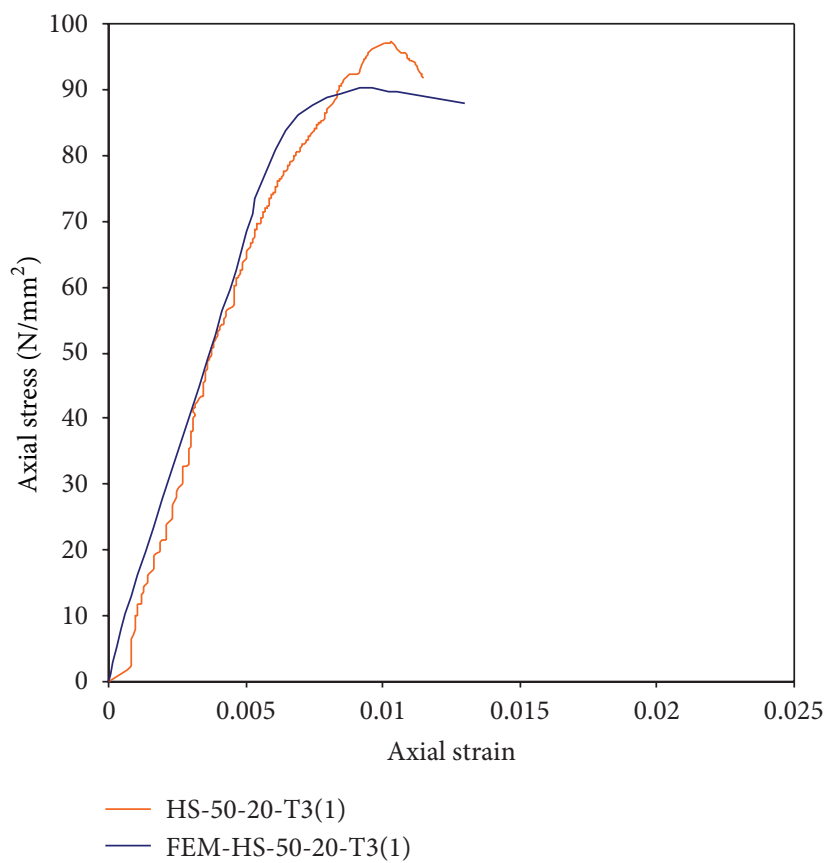

FIGURE 32: Comparison of experimental and computed axial stress-strain behaviours of HS-50-20-T3(1) columns.

control column, followed by inelastic behavior when increasing the load. In addition to this, behavior of those had good agreement with the experimental results. Until it reached the yield point, for all columns, it was found to be 2 to $4 \mathrm{~mm}$ less in axial deformation in the case of computational graphs compared with the experimental results as shown in Figures $29,30,31,32,33,34$, and 35 . The ultimate values obtained from numerical simulation fairly agreed with the experimental results and in addition the obtained values are $10 \%$ to $15 \%$ more than that of experimental results.

\section{Conclusions}

Experimental and numerical investigations on the behaviours of axially loaded tubular columns strengthened by CFRP strips with two types of spacing were presented in this paper. The finite element model was created by considering the geometric and material non linearities and the results were successfully verified against the experimental value. Based on the experimental and numerical results, the following conclusions and recommendations are drawn. 


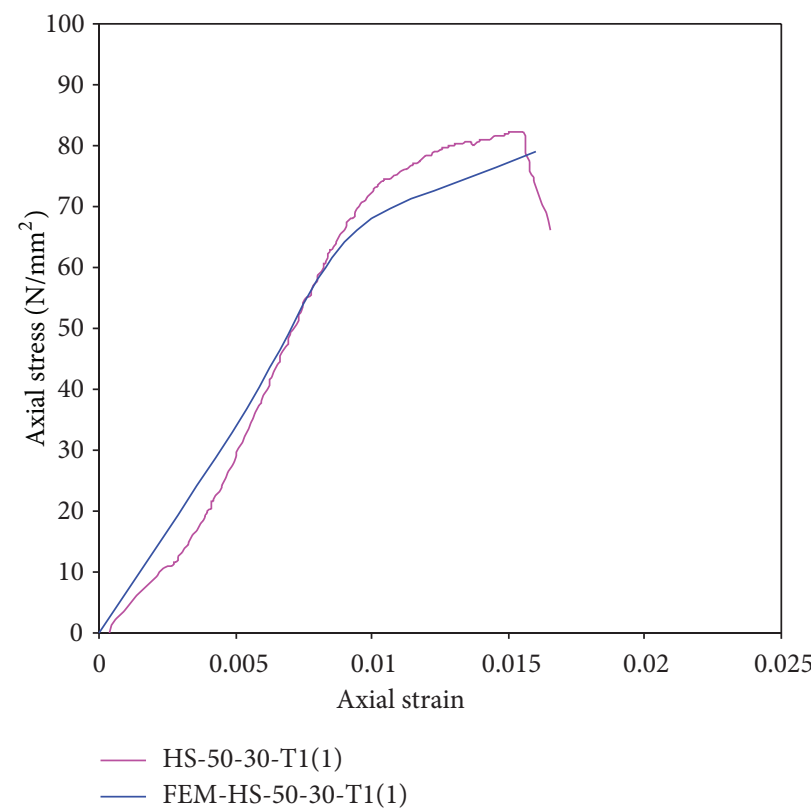

FIGURE 33: Comparison of experimental and computed axial stress-strain behaviours of HS-50-30-T1(1) columns.

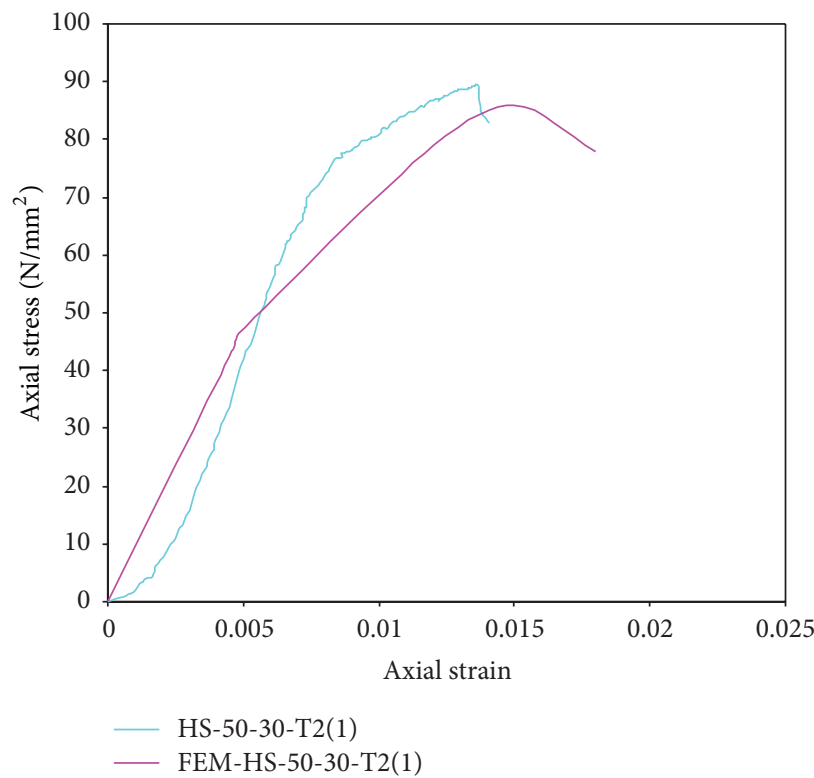

FIGURE 34: Comparison of experimental and computed axial stress-strain behaviours of HS-50-30-T2(1) columns.

(i) The increase in number of layers turned into failure mode of inward buckling rather than outward buckling. It is due to the external restraint effect by CFRP fabrics against outward buckling and as a result inward buckling of steel tube occurred.

(ii) No debonding of fibre was observed due to perfect bond between steel and fibre.

(iii) The external bonding of CFRP fabrics effectively delayed the local buckling of the steel tube and also reduced the axial shortening by providing confinement against the elastic deformation. (iv) The enhancements in restraining effect against axial deformation provided by the specimens such as HS50-30-T1(1), HS-50-30-T2(1), and HS-50-30-T3(1) were observed as 53.21\%, 92.39\%, and $125.67 \%$, respectively, compared to control column.

(v) The test results revealed that significant enhancement in ultimate strength can be achieved with the application of CFRP strips, especially up to $44.32 \%$ more than that of bare steel tube.

(vi) Compared to control column (CC1), the specimens HS-50-20-T1(1), HS-50-20-T2(1), and HS-50-20-T3(1) 


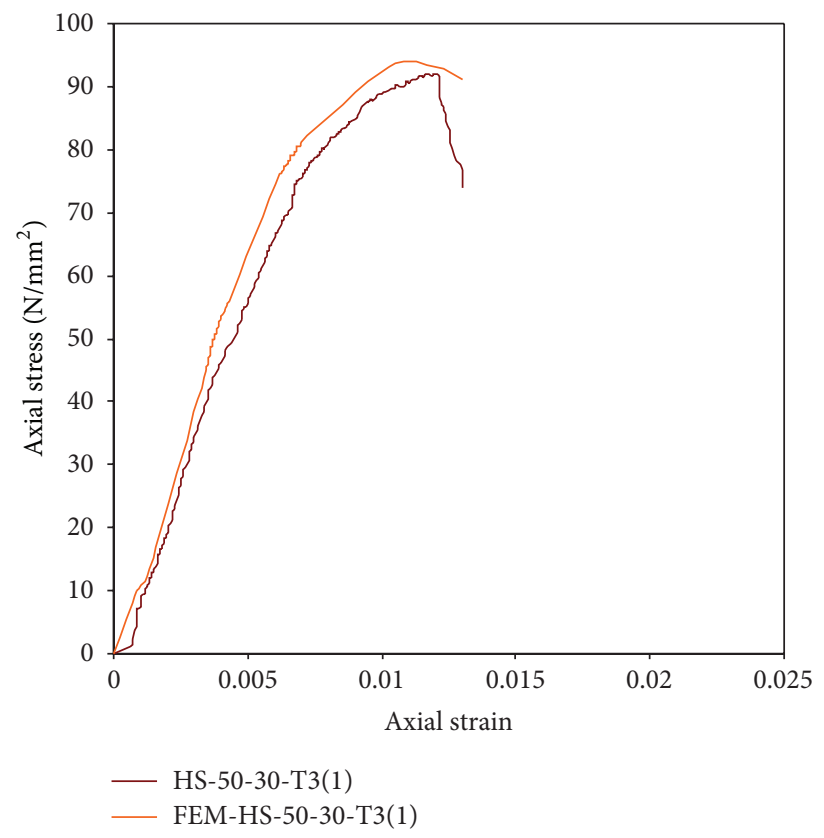

FIGURE 35: Comparison of experimental and computed axial stress-strain behaviours of HS-50-30-T3(1) columns.

TABLE 1: Maximum deformation, percentage of reduction in deformation, and increase in load carrying capacity.

\begin{tabular}{|c|c|c|c|c|c|}
\hline $\begin{array}{l}\text { Designation of } \\
\text { columns }\end{array}$ & $\begin{array}{l}\text { Failure load } \\
\qquad(\mathrm{kN})\end{array}$ & $\begin{array}{l}\text { Maximum axial } \\
\text { deformation } \\
(\mathrm{mm})\end{array}$ & $\begin{array}{c}\% \text { of reduction in } \\
\text { axial deformation } \\
\text { compared to CC2 } \\
(\mathrm{kN})\end{array}$ & $\begin{array}{l}\% \text { of increase in axial } \\
\text { load carrying capacity } \\
(\mathrm{kN})\end{array}$ & $\begin{array}{c}\text { Slenderness } \\
\text { value }(\lambda)\end{array}$ \\
\hline $\mathrm{CCl}$ & 546 & 8.29 & - & - & \multirow{3}{*}{0.46} \\
\hline $\mathrm{CC} 2$ & 564 & 8.35 & - & - & \\
\hline $\mathrm{CC} 3$ & 549 & 8.5 & - & - & \\
\hline HS-50-20-T1(1) & 709 & 7.91 & 68.68 & 25.71 & \multirow{3}{*}{0.35} \\
\hline HS-50-20-T1(2) & 692 & 7.45 & 65.34 & 22.69 & \\
\hline HS-50-20-T1(3) & 697 & 7.57 & 67 & 23.58 & \\
\hline HS-50-20-T2(1) & 764 & 7.46 & 116.88 & 35.46 & \multirow{3}{*}{0.31} \\
\hline HS-50-20-T2(2) & 747 & 6.93 & 111.98 & 32.44 & \\
\hline HS-50-20-T2(3) & 753 & 7.07 & 114.87 & 33.51 & \\
\hline HS-50-20-T3(1) & 814 & 6.12 & 163.40 & 44.32 & \multirow{3}{*}{0.28} \\
\hline HS-50-20-T3(2) & 803 & 6.02 & 161.56 & 42.37 & \\
\hline HS-50-20-T3(3) & 798 & 5.94 & 159.45 & 41.48 & \\
\hline HS-50-30-T1(1) & 690 & 9.27 & 53.21 & 22.34 & \multirow{3}{*}{0.35} \\
\hline HS-50-30-T1(2) & 682 & 9.12 & 50.96 & 20.92 & \\
\hline HS-50-30-T1(3) & 691 & 9.23 & 51.67 & 22.51 & \\
\hline HS-50-30-T2(1) & 749 & 8.18 & 92.39 & 32.8 & \multirow{3}{*}{0.31} \\
\hline HS-50-30-T2(2) & 741 & 8.02 & 91.43 & 31.38 & \\
\hline HS-50-30-T2(3) & 739 & 7.98 & 89.6 & 31.03 & \\
\hline HS-50-30-T3(1) & 770 & 7.02 & 125.67 & 36.52 & \multirow{3}{*}{0.28} \\
\hline HS-50-30-T3(2) & 764 & 7.03 & 123.7 & 35.46 & \\
\hline HS-50-30-T3(3) & 761 & 6.94 & 122.34 & 34.92 & \\
\hline
\end{tabular}


enhanced their axial load carrying capacity by $25.71 \%$, $35.46 \%$, and $44.32 \%$.

(vii) The external bonding of CFRP fabrics increases the thickness of the steel tube and decreases the slenderness value of the composite plate and as a result, the elastic buckling stress of the steel tube was increased.

(viii) The numerical results such as failure modes and load deformation behaviour fairly agreed with the experimental results. And also, the deformed shapes of the tubular columns obtained by numerical simulation fairly agreed with the corresponding experimental results.

(ix) It is suggested that external strengthening of tubular columns using normal modulus CFRP strips is a quite effective technique in increasing the load carrying capacity and stiffness of the tubular sections.

\section{Conflict of Interests}

The authors declare that there is no conflict of interests regarding the publication of this paper.

\section{References}

[1] G. L. Balazs and A. Borosnyói, "Long-term behavior of FRP," in Proceedings of the International Workshop on Composites in Construction: A Reality, pp. 84-91, American Society of Civil Engineers, Capri, Italy, 2001.

[2] L. Hollaway, Polymer Composites for Civil and Structural Engineering, Blackie Academic and Professional, London, UK, 1993.

[3] S. Peters, Handbook of Composites, Chapman \& Hall, London, UK, 2nd edition, 1998.

[4] L. Hollaway, Handbook of Polymer Composites for Engineers, Woodhead Publishing, Cambridge, UK, 1st edition, 1994.

[5] R. Sen and L. Liby, "Repair of steel composite bridge sections using CFRP laminates," US Department of Transportation Contract B-7932, University of South Florida, Tampa, Fla, USA, 1994.

[6] H. Jiao and X.-L. Zhao, "CFRP strengthened butt-welded very high strength (VHS) circular steel tubes," Thin-Walled Structures, vol. 42, no. 7, pp. 963-978, 2004.

[7] N. K. Photiou, L. C. Hollaway, and M. K. Chryssanthopoulos, "Strengthening of an artificially degraded steel beam utilising a carbon/glass composite system," Construction and Building Materials, vol. 20, no. 1-2, pp. 11-21, 2006.

[8] M. V. Seica and J. A. Packer, "FRP materials for the rehabilitation of tubular steel structures, for underwater applications," Composite Structures, vol. 80, no. 3, pp. 440-450, 2007.

[9] Z. Tao, L.-H. Han, and L.-L. Wang, "Compressive and flexural behaviour of CFRP-repaired concrete-filled steel tubes after exposure to fire," Journal of Constructional Steel Research, vol. 63, no. 8, pp. 1116-1126, 2007.

[10] Z. Tao and L.-H. Han, "Behaviour of fire-exposed concretefilled steel tubular beam columns repaired with CFRP wraps," Thin-Walled Structures, vol. 45, no. 1, pp. 63-76, 2007.

[11] M. Elchalakani and D. Fernando, "Plastic mechanism analysis of unstiffened steel I-section beams strengthened with CFRP under 3-point bending," Thin-Walled Structures, vol. 53, pp. 5871, 2012.
[12] K. Narmashiri, N. H. R. Sulong, and M. Z. Jumaat, "Failure analysis and structural behaviour of CFRP strengthened steel I-beams," Construction and Building Materials, vol. 30, pp. 1-9, 2012.

[13] M. M. A. Kadhim, "Effect of CFRP plate length strengthening continuous steel beam," Construction and Building Materials, vol. 28, no. 1, pp. 648-652, 2012.

[14] C. Wu, X. Zhao, W. H. Duan, and R. Al-Mahaidi, "Bond characteristics between ultra high modulus CFRP laminates and steel," Thin-Walled Structures, vol. 51, pp. 147-157, 2012.

[15] H. Al-Zubaidy, R. Al-Mahaidi, and X.-L. Zhao, "Experimental investigation of bond characteristics between CFRP fabrics and steel plate joints under impact tensile loads," Composite Structures, vol. 94, no. 2, pp. 510-518, 2012.

[16] P. Colombi and G. Fava, "Fatigue behaviour of tensile steel/ CFRP joints," Composite Structures, vol. 94, no. 8, pp. 2407-2417, 2012.

[17] J. Haedir, M. R. Bambach, X. L. Zhao, and R. Grzebieta, "Bending strength of CFRP-strengthened circular hollow steel sections," in Proceedings of the 3rd International Conference on FRP Composites in Civil Engineering (CICE '06), Miami, Fla, USA, 2006.

[18] M. C. Sundarraja and G. G. Prabhu, "Behaviour of CFST members under compression externally reinforced by CFRP composites," Journal of Civil Engineering and Management, vol. 19, no. 2, pp. 184-195, 2013.

[19] J. Haedir, M. R. Bambach, X.-L. Zhao, and R. H. Grzebieta, "Behaviour of thin-walled CHS beams reinforced by CFRP sheets," in Proceedings of the 4th International Structural Engineering and Construction Conference (ISEC4 '07), pp. 701-706, Melbourne, Australia, September 2007.

[20] X. Qu, Z. Chen, and G. Sun, "Experimental study of rectangular CFST columns subjected to eccentric loading," Thin-Walled Structures, vol. 64, pp. 83-93, 2013.

[21] A. Shaat and A. Fam, "Finite element analysis of slender HSS columns strengthened with high modulus composites," Steel and Composite Structures, vol. 7, no. 1, pp. 19-34, 2007.

[22] Z. Tao, Z.-B. Wang, and Q. Yu, "Finite element modelling of concrete-filled steel stub columns under axial compression," Journal of Constructional Steel Research, vol. 89, pp. 121-131, 2013. 

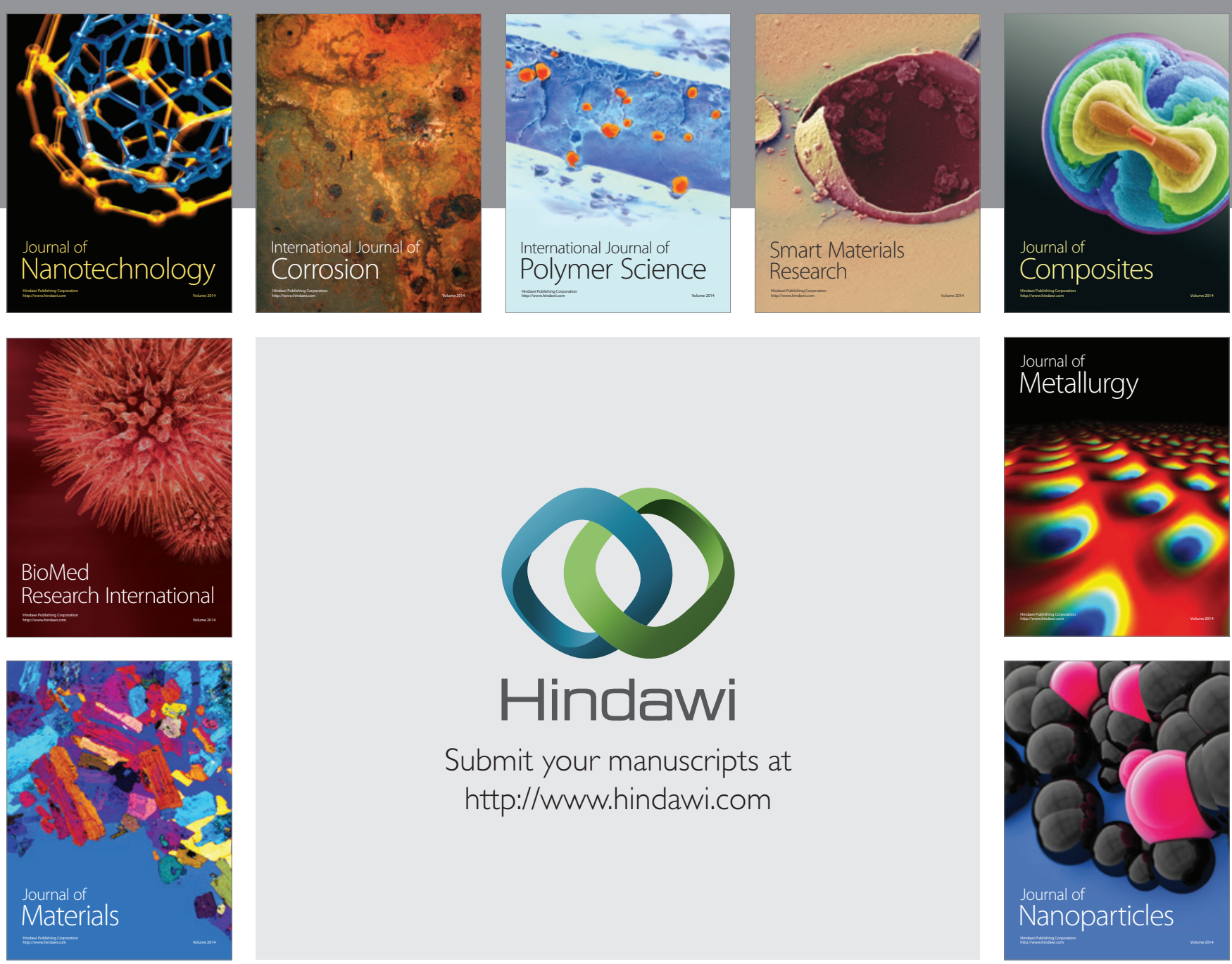

Submit your manuscripts at http://www.hindawi.com
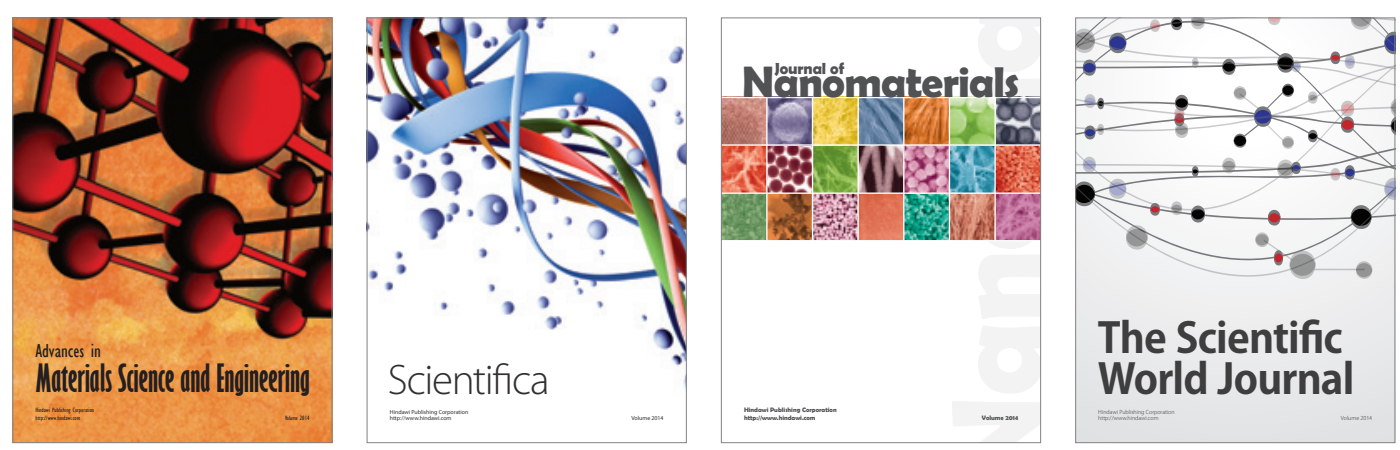

\section{The Scientific World Journal}
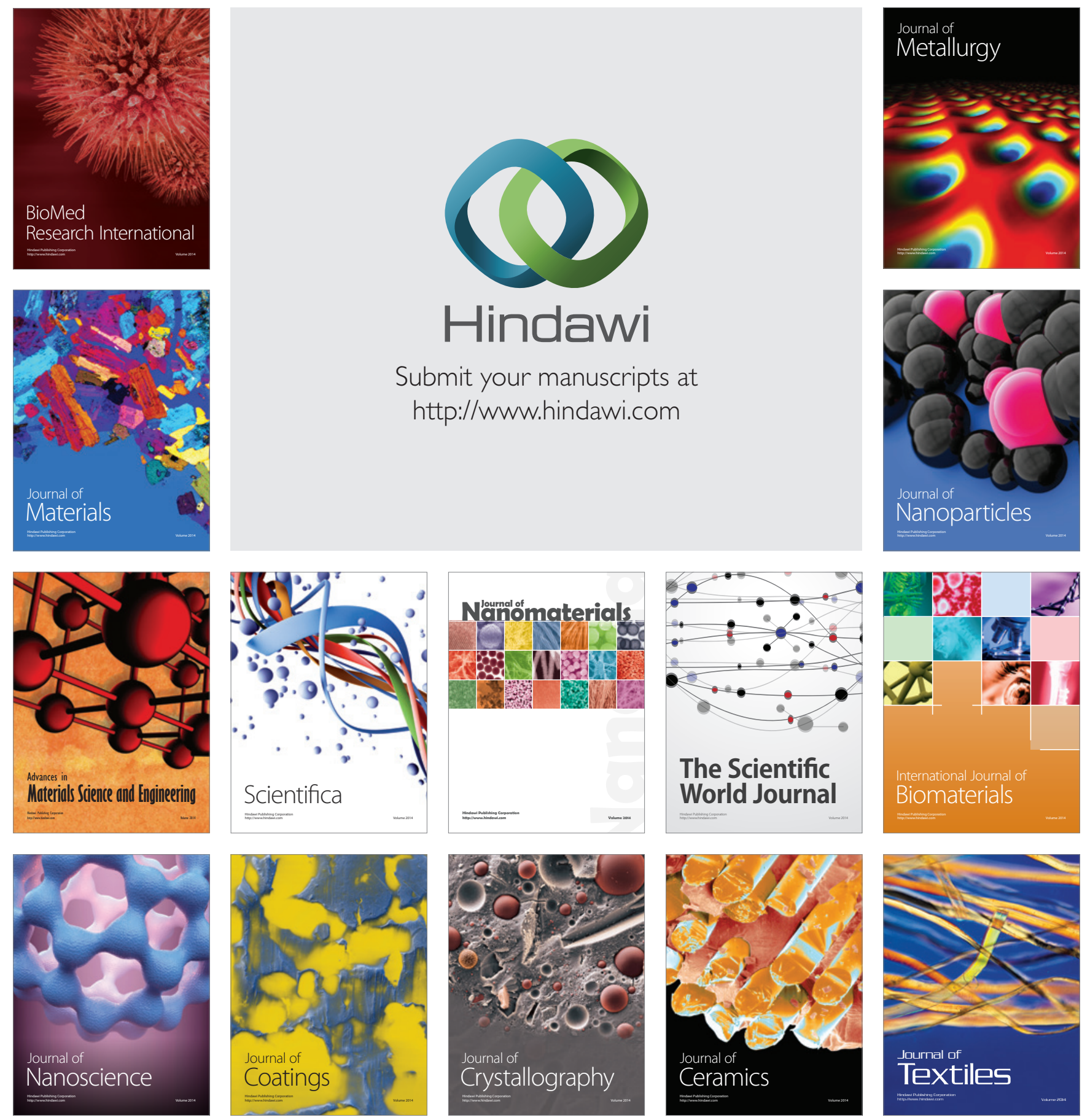